\title{
Large-scale transcriptomic analysis reveals that pridopidine reverses aberrant gene expression and activates neuroprotective pathways in the YAC128 HD mouse
}

Rebecca Kusko ${ }^{1 \dagger}$, Jennifer Dreymann ${ }^{2 \dagger}$, Jermaine Ross ${ }^{1}$, Yoonjeong Cha ${ }^{1}$, Renan Escalante-Chong ${ }^{1}$, Marta Garcia-Miralles ${ }^{3}$, Liang Juin Tan ${ }^{3}$, Michael E. Burczynski², Ben Zeskind ${ }^{1}$, Daphna Laifenfeld², Mahmoud Pouladi, ${ }^{3,5}$, Michal Geva², Iris Grossman ${ }^{2}$ and Michael R. Hayden 2,3,4,5*

\begin{abstract}
Background: Huntington Disease (HD) is an incurable autosomal dominant neurodegenerative disorder driven by an expansion repeat giving rise to the mutant huntingtin protein $(\mathrm{mHtt})$, which is known to disrupt a multitude of transcriptional pathways. Pridopidine, a small molecule in development for treatment of HD, has been shown to improve motor symptoms in HD patients. In HD animal models, pridopidine exerts neuroprotective effects and improves behavioral and motor functions. Pridopidine binds primarily to the sigma-1 receptor, (IC50 $100 \mathrm{nM}$ ), which mediates its neuroprotective properties, such as rescue of spine density and aberrant calcium signaling in HD neuronal cultures. Pridopidine enhances brain-derived neurotrophic factor (BDNF) secretion, which is blocked by putative sigma-1 receptor antagonist NE-100, and was shown to upregulate transcription of genes in the BDNF, glucocorticoid receptor (GR), and dopamine D1 receptor (D1R) pathways in the rat striatum. The impact of different doses of pridopidine on gene expression and transcript splicing in HD across relevant brain regions was explored, utilizing the YAC128 HD mouse model, which carries the entire human mHtt gene containing 128 CAG repeats.

Methods: RNAseq was analyzed from striatum, cortex, and hippocampus of wild-type and YAC128 mice treated with vehicle, $10 \mathrm{mg} / \mathrm{kg}$ or $30 \mathrm{mg} / \mathrm{kg}$ pridopidine from the presymptomatic stage (1.5 months of age) until 11. 5 months of age in which mice exhibit progressive disease phenotypes.

Results: The most pronounced transcriptional effect of pridopidine at both doses was observed in the striatum with minimal effects in other regions. In addition, for the first time pridopidine was found to have a dosedependent impact on alternative exon and junction usage, a regulatory mechanism known to be impaired in HD. In the striatum of YAC128 HD mice, pridopidine treatment initiation prior to symptomatic manifestation rescues the impaired expression of the BDNF, GR, D1R and CAMP pathways.

(Continued on next page)
\end{abstract}

\footnotetext{
* Correspondence: Michael.Hayden@teva.co.il; mrh@cmmt.ubc.ca

${ }^{\dagger}$ Rebecca Kusko and Jennifer Dreymann contributed equally to this study.

${ }^{2}$ Research and Development, Teva Pharmaceutical Industries Ltd, Netanya,

Israel

${ }^{3}$ Translational Laboratory in Genetic Medicine, Agency for Science,

Technology and Research, Singapore (A*STAR), Singapore 138648, Singapore

Full list of author information is available at the end of the article
}

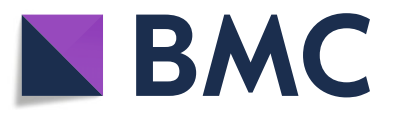

(c) The Author(s). 2018 Open Access This article is distributed under the terms of the Creative Commons Attribution 4.0 International License (http://creativecommons.org/licenses/by/4.0/), which permits unrestricted use, distribution, and

reproduction in any medium, provided you give appropriate credit to the original author(s) and the source, provide a link to the Creative Commons license, and indicate if changes were made. The Creative Commons Public Domain Dedication waiver (http://creativecommons.org/publicdomain/zero/1.0/) applies to the data made available in this article, unless otherwise stated. 
(Continued from previous page)

Conclusions: Pridopidine has broad effects on restoring transcriptomic disturbances in the striatum, particularly involving synaptic transmission and activating neuroprotective pathways that are disturbed in HD. Benefits of treatment initiation at early disease stages track with trends observed in the clinic.

Keywords: Huntington disease, Movement disorders, Neurodegeneration

\section{Background}

Huntington Disease (HD) is a progressive and neurological disorder caused by an autosomal dominant CAG trinucleotide expansion in the $H t t$ gene [1], characterized by psychiatric, cognitive and motor disturbances, manifesting usually between 40 and 50 years of age and worsening until death [2]. Htt plays a role in facilitating axonal transport of brain-derived neurotrophic factor (BDNF) in the corticostriatal pathway of the motor circuit in wild-type animals (Fig. 1a and b) [3]. Consistently, in animal models of HD, mHtt disrupts several neuronal functions including corticostriatal communication [4] and cortical release of BDNF [5] (Fig. 1c). Breakdown of corticostriatal transmission reduces synaptic activity of striatal neurons [6] and influences downstream signal transduction within the striatum. In addition to the deficiencies in BDNF-TrkB signaling previously reported in mouse models of $\mathrm{HD}[7,8]$, cyclic AMP (cAMP) signaling is disrupted in the striatum of presymptomatic R6/2 HD mice [9].

Pridopidine, a small molecule in development for the treatment of HD, improved motor function in HD patients in two large, double-blind, placebo-controlled studies (HART and MermaiHD) as exhibited by UHDRS-Total Motor Score (TMS), but did not meet primary endpoint of changes from baseline to week 12 in Modified Motor Score $[10,11]$. Pridopidine is a high affinity sigma-1 receptor [12] ligand and exerts low-binding affinity towards additional CNS receptors, such as Dopamine D2, Adrenergic a2C, Serotonin 5HT-1A and Histamine H3 [13, 14]. Further, an in-vivo PET imaging study in rats confirmed that pridopidine occupies the sigma- 1 receptor at low doses (3 and $15 \mathrm{mg} / \mathrm{kg})$, and the D2R only at higher doses $(60 \mathrm{mg} / \mathrm{kg})$. Pridopidine normalizes endoplasmic reticulum (ER) calcium levels in YAC128 corticostriatal co-cultures [15], mediated by the sigma-1 receptor (Fig. 1d). The sigma-1 receptor also mediates pridopidine-induced BDNF in rat neuroblastoma cells [15]. In the striatum of R6/2 HD mice [16, 17], pridopidine treatment increases BDNF protein levels in the striatum (Fig. 1d). Finally, a gene expression analysis in WT rat striatum demonstrates pridopidine induces differential expression (DE) of genes enriched for the BDNF, D1R, and glucocorticoid receptor pathways, presumably mediated via sigma-1 receptor activation.

The effect of different doses of chronic pridopidine treatment, initiated at pre-symptomatic stages, on gene expression and transcript splicing in the context of HD was evaluated using single nucleotide resolution RNA sequencing in YAC128 mice, examining specificity of effects across brain regions.

\section{Methods}

\section{Animals}

YAC128 HD mice [18] (referred to herein as YAC128), maintained on the FVB/N strain were used. Mice were bred and housed according to Garcia-Miralles 2017 [19]. All mouse experiments were performed with the approval of and in accordance with the Institutional Animal Care and Use Committee at the Biomedical Sciences Institute at the Agency for Science, Technology and Research. Pridopidine synthesized by Teva Pharmaceutical Industries was dissolved in sterile water for oral administration. Pridopidine or vehicle was given every day by an oral gavage for 5 days/week for 10 months starting at a presymptomatic stage (1.5 months of age). Mice were split into three treatment groups: vehicle (sterile water), $10 \mathrm{mg} / \mathrm{kg}$ of pridopidine ("low dose"), or $30 \mathrm{mg} / \mathrm{kg}$ of pridopidine ("high dose").

A second group of WT mice (C57BI6) were bred and housed at the Department of Experimental Medical Science of Lund University (Sweden), and treated with pridopidine $30 \mathrm{mg} / \mathrm{kg}$ for 10 days.

\section{Sample preparation and RNA extraction}

Mice were anaesthetised and perfused with ice-cold phosphate-buffered saline followed by ice-cold $4 \%$ paraformaldehyde in phosphate-buffered saline as described in Garcia-Miralles 2017 [19]. Brains were removed from YAC128 and WT, striatum, hippocampus, and cortex were frozen on dry ice, mounted with Tissue-TEK O.C.T. compound (Sakura, Torrance, CA, USA), and sliced coronally into $25-\mu \mathrm{m}$ sections on a cryostat (Microm HM 525, Thermo Fisher Scientific, Waltham, Massachusetts, USA). The sections were collected and kept in RNAlater solution (Ambion, AM7021) overnight at $4{ }^{\circ} \mathrm{C}$ and then stored at $-80{ }^{\circ} \mathrm{C}$ until use. Total RNA was isolated by EA Genomics from tissue biopsies from mouse brain regions using the miRNeasy mini kit (Qiagen). RNA was also extracted from blood samples of the same mice using RNeasy Protect Animal Blood Kit EA. RNA integrity was assessed using an Agilent Bioanaylzer and only RNA samples with RIN scores 


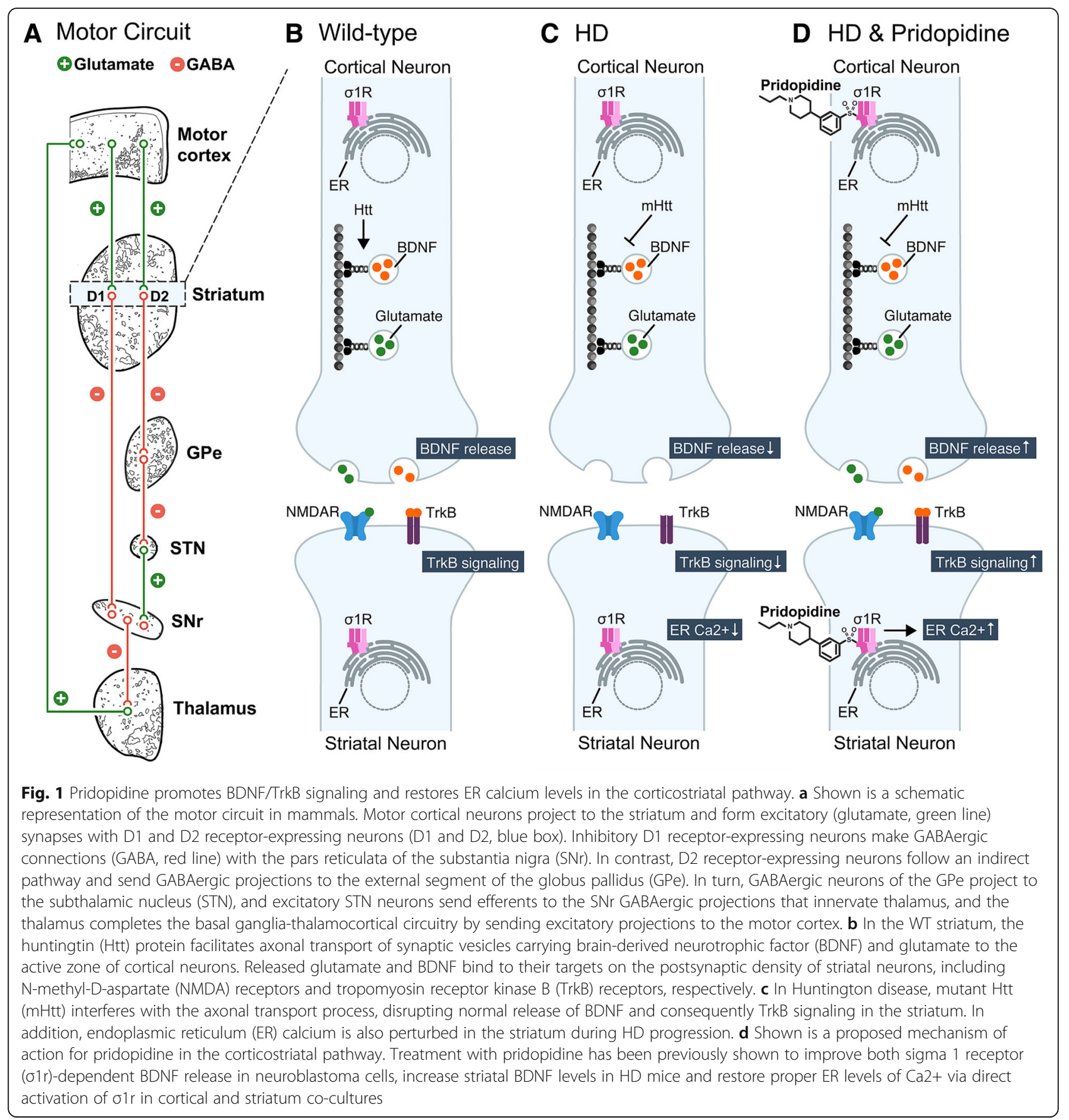

$>8$ were used. RNA samples were quantified by NanoDrop for RNAseq.

\section{RNA sequencing and mapping}

EA Genomics performed the RNA sequencing on both mouse studies: 1 . Striatum, hippocampus, and cortex of chronic pridopidine or vehicle treated YAC128 or WT mouse and 2. Blood from acute pridopidine treated WT mice. Sequencing was performed using the Illumina
TruSeq Stranded mRNA Kit with HiSeq 2x50nt paired end sequencing. Star v.2.5.0a was used to align FASTQ files [20], using the GRCm38 primary assembly annotation and standard options. PCA plots of the samples were used to select outliers and to adjust for possible covariates. Transcripts that had less than 10 reads on average were filtered out. CalcNormFactors from the edgeR R package [21] was used to normalize the counts via the TMM method. 


\section{RNAseq analysis}

Following the lead of MAQC [22], the limma v3.28.21 [23] R-package was used to transform and model the gene-level quantification data. Limma::voom was used to transform the count data to $\log 2$-counts per million and calculate the mean-variance relationship. Limma::ImFit was used to fit a linear model for each gene based on the experimental design matrix. Limma::eBayes was used to calculate the empirical Bayes moderated $t$-statistic for contrast significance. Multiple hypothesis adjusted $p$-values were calculated using limma::topTable, which implemented the Benjamini-Hochberg procedure to control FDR. In order to decrease the chance of finding a differential expression signature by chance, we utilized pvalue correction to adjust for the number of hypothesis (genes) we were testing Differential expression contrasts were independently calculated for all three tissues between: A. untreated YAC128 and untreated WT samples, B. $30 \mathrm{mg} / \mathrm{kg}$ pridopidine YAC128 and untreated YAC128 samples, C. $10 \mathrm{mg} / \mathrm{kg}$ pridopidine YAC128 and untreated YAC128 samples, D. $30 \mathrm{mg} / \mathrm{kg}$ pridopidine WT and untreated WT samples. In order to compare the magnitude of, and concordance between brain transcriptional signatures and peripheral blood profiles, indicative of the potential to develop biomarkers of disease and response to therapy, we examined samples obtained from a 10-day treatment study, contrasting $30 \mathrm{mg} / \mathrm{kg}$ pridopidine WT and untreated WT blood (E.).

To test whether the treatment gene expression signature is enriched for relevant pathways, Gene Set Enrichment Analysis (GSEA) [24] was used. All genes tested for differential expression were ranked by limma generated $\mathrm{t}$-statistic for a given contrast. This was input as the "ranked list" in GSEA pre-ranked analysis. Moreover, gene sets were made from lists of differentially expressed genes from literature [25-27] in order to assess whether genes regulated by pridopidine enriched for genes downstream of Dopamine 1 Receptor, BDNF, and Glucocorticoid Receptor. In order to further filter before pathway analysis, we employ a strict version of what is recommended by MAQC, combining a fold change cutoff with an adjusted pvalue cutoff [28]. Hypothesis free broad pathway and transcription factor enrichment was done using Enrichr [29], selecting striatal differential expressed genes combining a fold change with a $p$-value cutoff according to MAQC guidance [28] (absolute linear fold change $>1.25$ and adjusted $p$-value $<0.05$ ). For all differential expression, splicing, pathway, and transcription factor analyses we consider "significant" to mean Adj. pval $<0.05$ unless otherwise stated.

A signature of genes modulated in HD patient tissue was assembled through a meta-analysis of LIMMA results from two publicly available gene expression datasets from caudate nucleus of 48 total HD patients and
42 controls (GSE26927 and GSE3790). A signature of genes modulated in YAC128 striatum was assembled using LIMMA results from 9 YAC128 mice and 6 WT mice, aged 11.5 months. The HD and YAC128 disease signatures were queried against our expression signatures for pridopidine in striatum of YAC128 mice treated for 10 months at 10 or $30 \mathrm{mg} / \mathrm{kg}$ daily using cosine similarity of the moderated t-statistic to assess gene expression reversal.

\section{Exon and splice junction analysis}

Star aligned reads were processed using Quality of RNA-Seq Toolset (QoRTS) with the parameter -stranded. A flat annotation file for GRCm38.p4 was generated using QoRTs and used for subsequent analysis. Differential usage of exon and splice junction (DUEJ) analysis was performed using the JunctionSeq Bioconductor package. JunctionSeq uses a multivariate generalized linear model using a negative binomial distribution to detect exons and splice junctions whose expression changes between conditions relative to the expression of their respective genes. To determine differential usage of exons and splice junctions an adjusted $p$-value cutoff of 0.05 was used.

\section{Results \\ Pridopidine induces striatal gene expression changes in YAC128 HD mice}

In a previous study, behavioral and motor effects of pridopidine were evaluated longitudinally, demonstrating improvements in motor coordination, reduced anxiety and depressive like phenotypes, concordant with reversal of specific striatal transcriptional deficits [19]. Here, to characterize the underlying mechanisms, the effect of pridopidine on the YAC128 HD model, gene expression was assessed through the comparison of transcriptomic profiles in YAC128 mice treated with pridopidine (10 or $30 \mathrm{~kg} / \mathrm{mg}$, p.o.) or vehicle (5 days/week) and WT mice treated with $30 \mathrm{mg} / \mathrm{kg}$ of pridopidine or vehicle (5 days/ week). In parallel with the previously described behavioral study [19], animals were treated starting at 1.5 months of postnatal life (presymptomatic) and sacrificed at 11.5 months of age (robust HD phenotype). Gene expression from the striatum, hippocampus, and cortex was evaluated using large RNAseq.

To further identify disease-specific gene expression patterns, vehicle-treated YAC128 mice were compared to vehicle-treated wild-type (WT) mice, demonstrating gene expression changes largely restricted to the striatum. We identified 1346 differentially expressed genes (DEGs) in the striatum (Adj. $p$-val $<0.05$, Table 1) compared to 340 DEGs in the hippocampus and 7 DEGs in the cortex (Adj. $p$-val $<0.05$, Table 1). Fold change and pvalue ranges are in Additional file 1: Table S1. 
Table 1 Summary of genes with differential expression or alternative junction/exon usage

\begin{tabular}{llll}
\hline Number of Differentially Expressed Genes & & \\
\hline Contrast & Striatum & Hippocampus & Cortex \\
\hline YAC128 Veh-WT Veh & 1346 & 340 & 7 \\
YAC128 $10 \mathrm{mg} / \mathrm{kg}-$ YAC128 Veh & 73 & 0 & 0 \\
YAC128 $30 \mathrm{mg} / \mathrm{kg}-$ YAC128 Veh & 221 & 0 & 0 \\
WT $30 \mathrm{mg} / \mathrm{kg}-$ WT Veh & 17 & 0 & 0 \\
Number of Genes with Alternative Junction/Exon usage & \\
YAC128 Veh-WT Veh & 39 & 14 & 4 \\
YAC128 10 mg/kg-YAC128 Veh & 1 & 0 & 0 \\
YAC128 30 mg/kg-YAC128 Veh & 565 & 1 & 4 \\
WT $30 \mathrm{mg} / \mathrm{kg}-$ WT Veh & 0 & 4 & 2 \\
\hline
\end{tabular}

An Adj. p-val cutoff of 0.05 was used as pre-requisite criterion to identify differentially expressed genes (top) and alternative exon/junction usage cases (bottom) for each contrast and each tissue

To test if disease progression and/or pridopidine induced gene expression signatures can also be observed outside of the brain, and thus potentially produce biomarkers useful for therapeutic development and monitoring, transcriptomic signals were examined in blood from WT mice treated with pridopidine for 10 days. Only one gene was found to be significantly differentially expressed between $30 \mathrm{mg}$ and vehicle treated mice (IL7R adj pval $=0.03$, linear FC 2.11).

In the YAC128 HD model, a dose-dependent effect of pridopidine (vs vehicle) was observed in striatum (Adj. p-val <0.05, Table 1): $10 \mathrm{mg} / \mathrm{kg}$ of pridopidine treatment induced significant differential expression of 73 genes, with $30 \mathrm{mg} / \mathrm{kg}$ pridopidine inducing roughly three times as many genes as the $10 \mathrm{mg}$ dose (221 striatal DEGs, Adj. $p$-val $<0.05$, Table 1, 55 genes overlap the two lists). No detectible differences in gene expression were observed in the YAC128 hippocampus or cortex after pridopidine treatment (Adj. $p$-val $<0.05$, Table 1 ), suggesting that a robust pridopidine signature is brain compartment specific and not an off target effect. In WT mice, treatment with $30 \mathrm{mg} / \mathrm{kg}$ of pridopidine resulted in striatal differential expression of only 17 genes (Adj. $p$-val $<0.05$, Table 1). Among these genes, four were also described in a recent microarray study that identified 16 DEGs in the striatum of wild-type rats after treatment with pridopidine $(60 \mathrm{mg} / \mathrm{kg})$ [30]. The four overlapping genes are Junb, Egr2, Nr4a1, and Per1. With the exception of Junb, these genes are also downregulated in the YAC128 mouse model of HD. Taken together, the data demonstrate that the effect of pridopidine on gene expression is more pronounced in a disease model than in WT animals, and is primarily limited to the striatum.

\section{Pridopidine reverses YAC128 HD mouse model and human HD disease gene expression signatures}

We next quantified the extent to which the genes with expression modulated by 10 and $30 \mathrm{mg} / \mathrm{kg}$ of pridopidine reverse: 1) genes with expression modulated in HD patient tissue relative to healthy controls (from GSE26927 and GSE3790, described in methods), and 2) genes with expression modulated in YAC128 striatum compared to WT controls. In agreement with Garcia-Miralles 2017 [19], we observed that treatment with 10 and $30 \mathrm{mg} / \mathrm{kg}$ of pridopidine significantly reversed the YAC128 disease signature (Fig. 2, Table 2). Moreover, in this study, we additionally observe reversal of our HD patient signature (derived from GSE26927 and GSE3790). The results demonstrate the effectiveness of pridopidine to reverse genes modulated in human HD and the YAC128 mouse model of HD.

BDNF, GR, and D1R pathways are downregulated in $\mathrm{HD}[5,9,31]$, while pridopidine upregulates these pathways in WT rat striatum [30]. We investigated whether pridopidine upregulation of these pathways is recapitulated in WT and/or YAC128 mice. We performed Gene Set Enrichment Analysis (GSEA) using manually-curated BDNF, GR, and D1R gene sets. In YAC128 mice, we observed the expected reduction of the BDNF pathway via negative GSEA enrichment in the cortex and striatum, along with downregulation of the D1R pathway in the cortex (Adj. $p$-val $<0.05$, Fig. 3). Consistent with previous reports, GSEA pathway analysis revealed positive enrichment of BDNF, GR, and D1R pathway genes in WT mouse striatum after $30 \mathrm{mg} / \mathrm{kg}$ pridopidine treatment (Adj. $p$-val <0.05, Fig. 3). Enrichment analysis also confirmed upregulation of the BDNF pathways in the

Table 2 Pridopidine treatment signal significantly reverses YAC128 HD signal. Numbers shown are adjusted p-values from Gene Set Enrichment Analysis

\begin{tabular}{lllll}
\hline Dose & Direction & Striatum & Hippocampus & Cortex \\
\hline $10 \mathrm{mg} / \mathrm{kg}$ & Up in YAC128, Down with pridopidine & $3.58 \mathrm{E}-04$ & $3.78 \mathrm{E}-04$ & $2.40 \mathrm{E}-04$ \\
& Down in YAC128, Up with pridopidine & $3.64 \mathrm{E}-04$ & $4.99 \mathrm{E}-02$ & $2.40 \mathrm{E}-04$ \\
$30 \mathrm{mg} / \mathrm{kg}$ & Up in YAC128, Down with pridopidine & $3.15 \mathrm{E}-04$ & $3.46 \mathrm{E}-04$ & $2.35 \mathrm{E}-04$ \\
& Down in YAC128, Up with pridopidine & $3.37 \mathrm{E}-04$ & $3.53 \mathrm{E}-03$ & $2.35 \mathrm{E}-04$ \\
\hline
\end{tabular}

Reversal was significant for all doses of pridopidine across the striatum, hippocampus, and cortex of YAC128 mice 


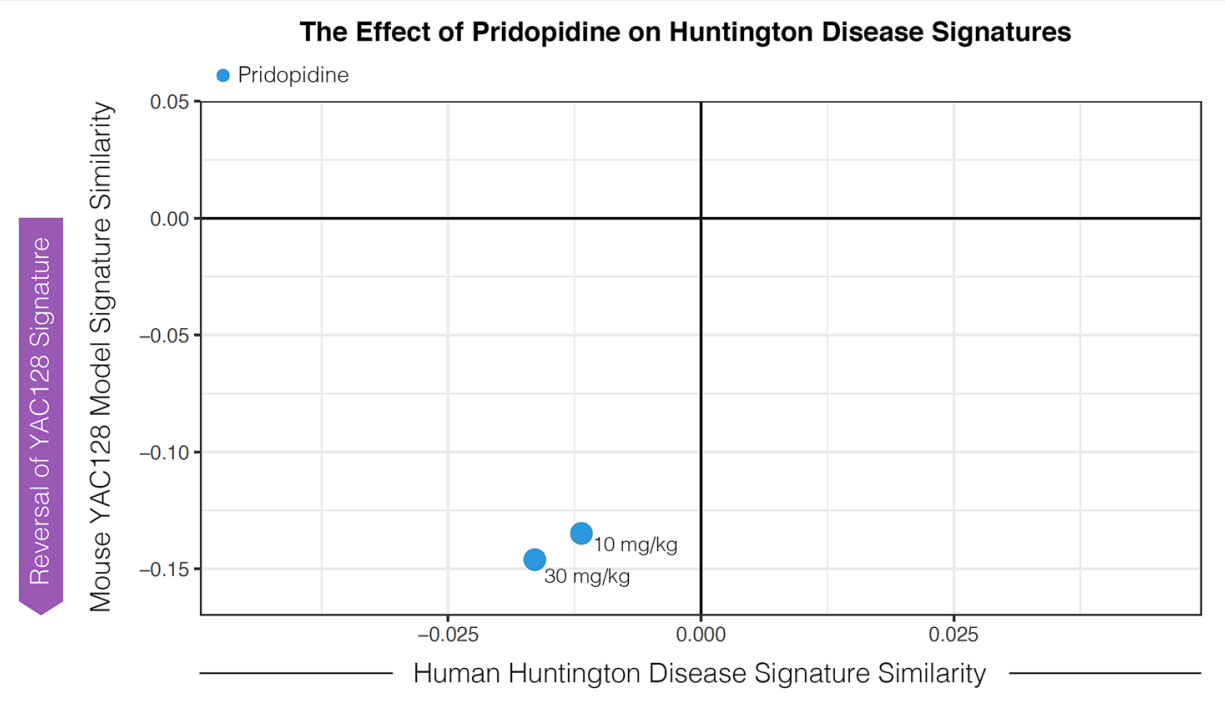

Reversal of Human HD Signature

Fig. 2 Pridopidine reverses mouse YAC128 and human Huntington disease signatures. Pridopidine reversal of genes modulated in the YAC128 mouse model of Huntington disease (y-axis) as a function of human Huntington disease (x-axis). The blue dots represent 10 and $30 \mathrm{mg} / \mathrm{kg}$ dose of pridopidine

striatum, hippocampus, and cortex of YAC128 animals after treatment with either the 10 or $30 \mathrm{mg} / \mathrm{kg}$ dose of pridopidine (Adj. p-val $<0.05$, Fig. 3). In addition, D1R and GR pathways were positively enriched across all three tissues after either 10 or $30 \mathrm{mg} / \mathrm{kg}$ treatment of pridopidine, with two exceptions: no significant enrichments were observed 1) for the GR pathway in the cortex after $10 \mathrm{mg} / \mathrm{kg}$ treatment; and 2) for the D1R pathway in the hippocampus after $30 \mathrm{mg} / \mathrm{kg}$ treatment.

\section{Database-driven enrichment analysis reveals that pridopidine enhances relevant biological pathways altered in the YAC128 HD striatum}

While GSEA provides a robust approach for pathway analysis, the method is limited to the manual curation of gene sets. To expand systematically our search for biological processes modulated by pridopidine, we next employed the enrichment tool Enrichr, which utilizes several comprehensive datasets including the Gene Ontology (GO) database. Our analysis focused on DEGs identified in the striatum, where the effect of pridopidine was most pronounced. Enrichment analysis was performed to identify pathways that are downregulated in vehicle-treated YAC128 and upregulated in pridopidine-treated YAC128 mice. Top 10 (of 63) downregulated pathways in the YAC128-vehicle mice (Adj. p-val $<0.05$, Additional file 2: Table S2), include impaired synaptic transmission processes, MAP kinase activity, cAMP metabolism, and adenylate cyclase signaling, as well as response to amphetamine and cocaine (Adj. $p$-val $<0.05$, Fig. 4).
Pridopidine treatment upregulated cAMP and kinase activity pathways impaired in the YAC128 striatum. Enrichment analysis revealed upregulation of enhanced biological pathways in the YAC128 striatum, with the cAMP response biological process showing a robust, statistically significant signal, ranking 1st after treatment with either the 10 or $30 \mathrm{mg} / \mathrm{kg}$ dose of pridopidine (Adj. p-val= 2.49E-09 and 2.53E-09 respectively, Fig. 4). For both doses of pridopidine, other highly ranked biological processes include negative regulation of kinase and phosphorylation (Adj. p-val < 0.05, Fig. 4 and Additional file 2: Table S2). In the YAC128 striatum, there were no significant GO enrichments using DEGs 1) upregulated after vehicle treatment, or 2) downregulated after pridopidine treatment. In wild-type mice, pridopidine induced enrichment of cAMP and p38-MAPK regulation pathways (Adj. $p$-val $<0.05$, Fig. 4, Additional file 2: Table S2).

To identify enriched transcriptional factors (TFs) constituting upstream regulatory mechanisms, ENCODE and ChIP Enrichment Analysis (ChEA) databases were queried via Enrichr using DEGs that were: 1) downregulated in the YAC128 versus WT striatum, or 2) upregulated in the pridopidine treatment group. TF analysis of genes downregulated in YAC128 striatum revealed enrichment for gene targets of the transcription factor SUZ12 (Adj. p-val $<0.05$, Additional file 3: Table S3). These enrichments are consistent with previous studies showing that SUZ12 is perturbed due to epigenetic dysregulation in HD [32].

TF analysis of DEGs upregulated in the pridopidine treatment group revealed CREB1 transcription factor as a highly significantly enriched gene set $(10$ and $30 \mathrm{mg} /$ 


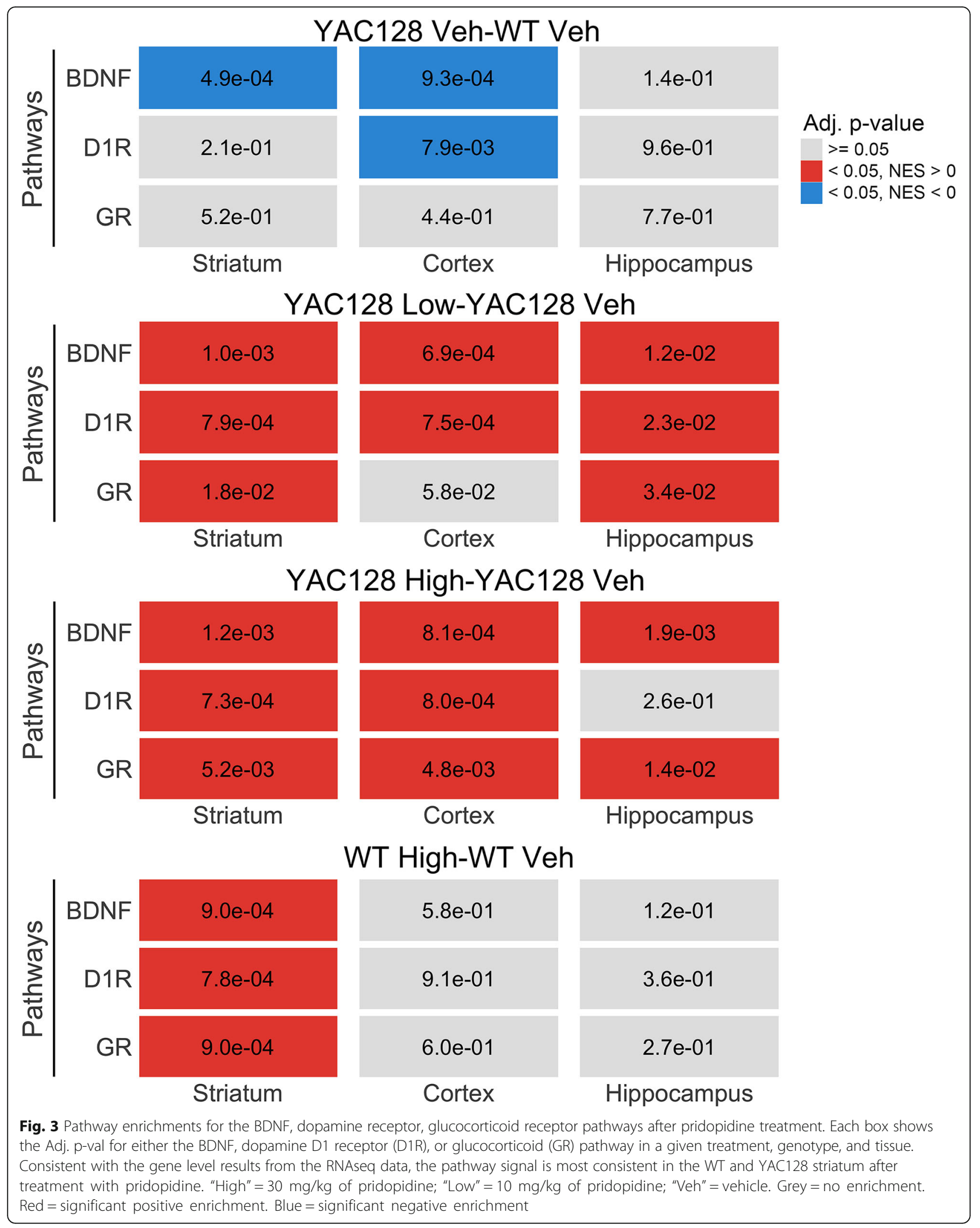




\section{Top 10 enriched $\mathbf{G O}$ biological processes \\ YAC128 Veh - WT Veh}
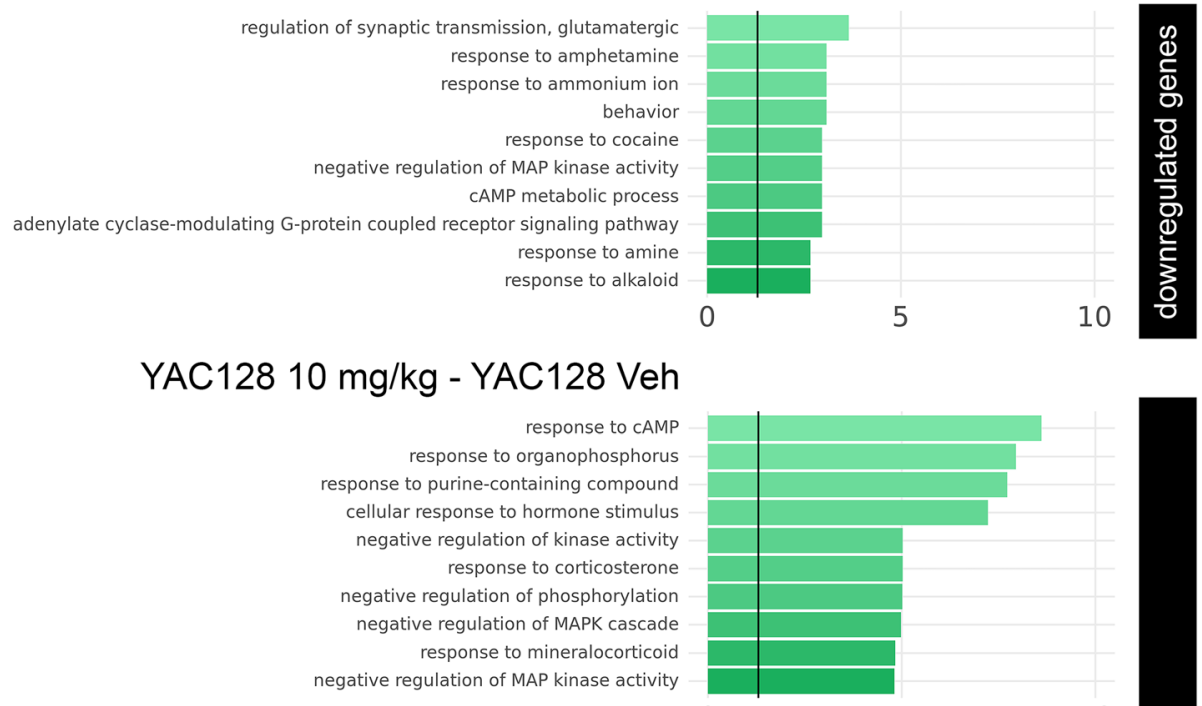

YAC128 $30 \mathrm{mg} / \mathrm{kg}$ - YAC128 Veh
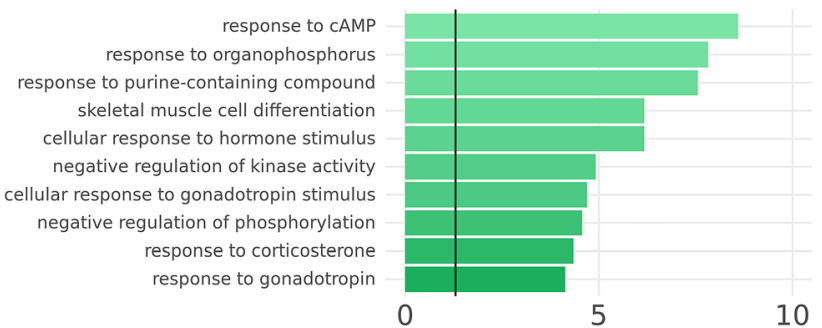

WT $30 \mathrm{mg} / \mathrm{kg}$ - WT Veh
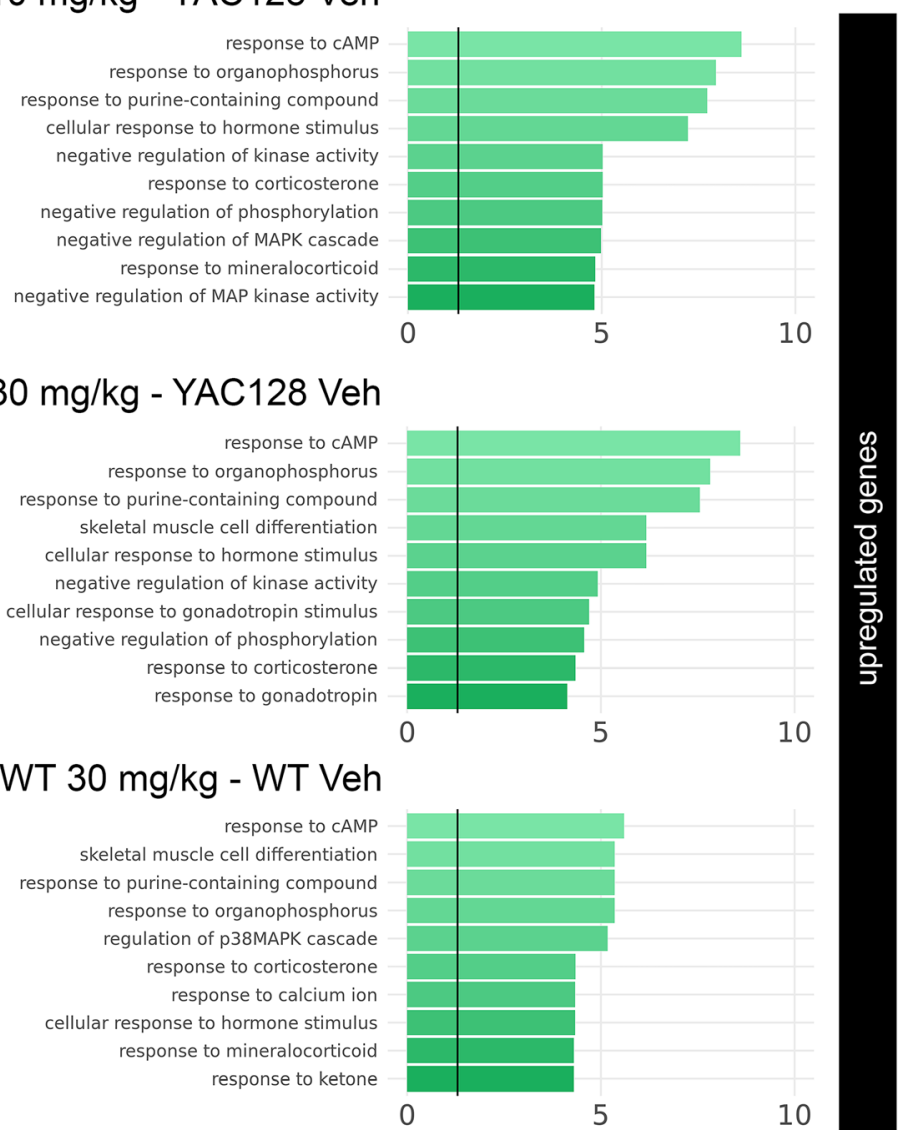

$-\log 10($ Adj. P-value)

Fig. 4 Top 10 enriched Gene Ontology (GO) biological process pathways. Pathway enrichment was performed on striatal DEGs downregulated in vehicle-treated YAC128 mice (top panel), striatal DEGs upregulated after treatment with $10 \mathrm{mg} / \mathrm{kg}$ pridopidine in YAC128 (second panel), striatal DEGs upregulated after treatment with $30 \mathrm{mg} / \mathrm{kg}$ pridopidine in YAC128 (third panel), and striatal DEGs upregulated after treatment with $10 \mathrm{mg} /$ kg pridopidine in WT (second panel)

$\mathrm{kg}$ ) in the YAC128 striatum (Adj. p-val $<0.05$, Additional file 3: Table S3). This is consistent with both disrupted CREB activity in HD [33] and the identification of upregulation of cAMP-response genes after pridopidine treatment (Adj. p-val $<0.05$, see Additional file 2: Table S2). CREB1 gene set was also enriched after $30 \mathrm{mg} / \mathrm{kg}$ pridopidine treatment in WT striatum (Adj. $p$-val $<0.05$, Additional file 3: Table S3). Taken together, these observations suggest that pridopidine treatment may induce gene expression regulated via the CREB transcriptional pathway, known to be disrupted in HD.

Pridopidine reverses compromised CAMP response gene activity in the YAC128 HD striatum

In YAC128 striatum, pridopidine enrichment of cAMP response is composed of 8 upregulated genes (Dusp1, 
Egr1, Egr2, Egr4, Fos, Fosb, Fosl2, and Junb) after treatment with $10 \mathrm{mg} / \mathrm{kg}$ of pridopidine, and 9 upregulated genes (Dusp1, Egr1, Egr2, Egr3, Egr4, Fos, Fosb, Fosl2, and $J u n b$ ) after treatment with $30 \mathrm{mg} / \mathrm{kg}$ of pridopidine (Adj. p-val $<0.05$, Figs. 5 and 6). In addition, we also identified another cAMP-regulated gene, Rgs2 [34], upregulated after pridopidine treatment (Fig. 6). Five of these genes (Dusp1, Egr1, Egr2, Fosl2, and Rgs2) are downregulated in the striatum of vehicle-treated YAC128 mice (Adj. p-val<0.05, Fig. 5, Additional file 4: Table S4). qPCR confirmed pridopidine reversed the expression of Dusp1, and Egr2, and Fosl2 (Adj. p-val < 0.05, Fig. 5 and Additional file 4: Table S4).

\section{Pridopidine modulates exon and transcript junction in the striatum of HD mice}

Alternative splicing represents a key transcriptomic regulatory mechanism required for many basic cellular functions. Recent evidence suggests alternative splicing may be perturbed in HD. To determine if alternative splicing also occurs in YAC128 mice, we performed differential usage of exon and splice junction (DUEJ) analysis in the striatum, hippocampus, and cortex. In YAC128 mice compared to WT controls, we observed 39, 14, and 4 DUEJs in striatal, hippocampal, and cortical genes, respectively (all Adj. p-val $<0.05$, Table 1 ). In concordance with gene level differential expression, the majority of DUEJ occurred in the striatum.

We then examined whether treatment with pridopidine compared to vehicle induces DUEJ in the brains of WT and YAC128 mice. In the YAC128 striatum, pridopidine induced dose-dependent DUEJ, with 565 genes significant in the $30 \mathrm{mg} / \mathrm{kg}$ group compared to only a single gene in $10 \mathrm{mg} / \mathrm{kg}$ pridopidine-group (both Adj. p-val $<0.05$, Table 1$)$. In WT mice, treatment with pridopidine did not lead to any DUEJ differences in striatum (all Adj. p-val $<0.05$, Table 1). Eleven genes (Kifap3, Zwint, Cltc, Rtn1, Acin1, Ano3, Dclk1, Ppp3ca, Atp2b2, Arpp19, and Arpp21) demonstrated significant DUEJ and reversal after $30 \mathrm{mg} / \mathrm{kg}$ pridopidine treatment in the YAC128 striatum (Adj. $p$-val<0.05). Pridopidine induced minimal to no DUEJ changes in hippocampus and cortex (Table 1). These results are consistent with the dose-dependent effect of pridopidine on gene expression restricted to the YAC128 striatum.

Pathway analysis on the 565 genes demonstrating DUEJ after $30 \mathrm{mg} / \mathrm{kg}$ pridopidine treatment in YAC128 mice showed enrichments for pathways previously described to be involved in pridopidine's mechanism of action such as calcium regulation (adj.pval $=3.6 \mathrm{E}-06$ ), and Synaptic Vesicle (3.4E-06). Additional pathways of interest previously reported as part of pridopidine's mechanism of action include: BDNF signaling and $G$ protein signaling, (Adj. $p$-val $<0.05$, Fig. $7 \mathrm{a}, \mathrm{b}$ and
Additional file 5: Table S5). Taken together, these results demonstrate that the $30 \mathrm{mg} / \mathrm{kg}$ of pridopidine induces exon and junction level changes in pathways that are relevant to $\mathrm{HD}$ pathology.

\section{Discussion}

It has recently been demonstrated that $30 \mathrm{mg} / \mathrm{kg}$ of pridopidine rescues motor behavioral deficits in YAC128 mouse model of HD [19]. To identify potential mechanisms by which pridopidine confers motor benefits, this study focuses on pridopidine induced changes in transcription across multiple brain regions and dose regimens. To characterize the functional relevance of transcriptomic changes, RNAseq data was analyzed for expression signaling, as well as splice variant modifications in pre-specified pathways, as well as across the genome unbiasedly. Testing was performed on WT and YAC128 striatum, cortex, and hippocampus after treatment with vehicle, 10 or $30 \mathrm{mg} / \mathrm{kg}$ pridopidine from a presymptomatic stage through disease progression. Both doses of pridopidine had a significant effect on gene and transcript levels in the striatum, with modest to unobserved effects in the cortex and hippocampus. However, the transcriptional effect of pridopidine in YAC128 striatum is dose-dependent. The two doses tested herein suggest linearity of the effect, which future studies employing additional doses will serve to shed further light on. While this study cannot directly query whether pridopidine's behavioral benefits are transcriptionally mediated, the fact that pridopidine's main transcriptomic effect is detected in the striatum supports this hypothesis. Moreover, the dose dependent functional expression signals induced by pridopidine track well with the dose-dependent behavioral benefits induced it induces at parallel experimental conditions (Garcia-Miralles et al., 2017). Lastly, genes with perturbed expression in YAC128 pathology are oppositely modulated by pridopidine in the striatum, far more so than expected by chance.

The transcriptional footprint of pridopidine demonstrates a reversal of the disease-specific gene expression and alternative splicing. The disease mechanisms reversed by pridopidine include critical neuroprotective pathways such as BDNF, D1R and glucocorticoid pathways previously reported. qPCR confirmed differential expression of many genes in these pathways. In addition, pridopidine induced gene expression triggered by cAMP transduction, also supported by modulation of downstream transcription factors (e.g. CREB1). Together, these findings provide robust data to demonstrate pridopidine restores mechanisms impaired in HD, specifically in the striatum.

Previous studies reported rescue of several aspects of HD, including phenotype and behavior, in the YAC128 mouse 

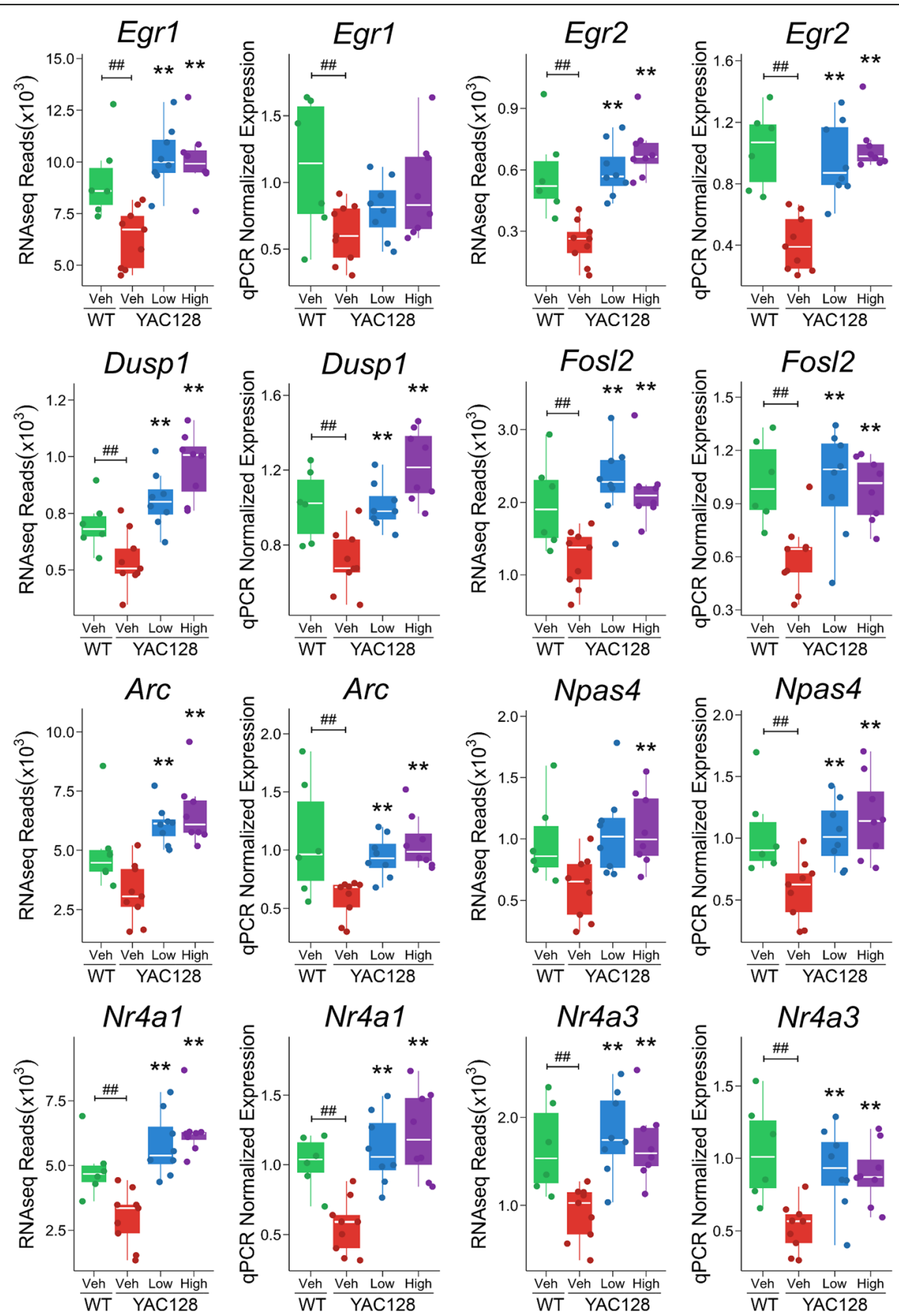

Fig. 5 qPCR validation of differential expression of striatal genes in YAC128 mice. Shown are RNAseq and qPCR results for genes differentially expressed in the striatum of YAC128 mice after pridopidine treatment. "**" and "\#\#" represent significant (Adj. p-val < 0.05) differential expression in YAC128 Veh-WT Veh and YAC128 Low/High-YAC128 Veh contrasts, respectively. "High" = 30 mg/kg of pridopidine; "Low" = $10 \mathrm{mg} / \mathrm{kg}$ of pridopidine; "Veh" = vehicle

through BDNF overexpression [35]. Dexamethasone, a glucocorticoid that activates the GR pathway, also dampens disease progression in a HD animal model [36]. Both 10 and $30 \mathrm{mg} / \mathrm{kg}$ pridopidine treatment in YAC128 mice significantly induced the BDNF, GR and D1R pathways in the striatum, hippocampus, and cortex, consistent with prior reports in WT rat [30]. As pridopidine does not directly bind GR (internal data, not shown), it suggests that the upregulation of the GR pathway may be indirect. Pridopidine increases dopamine efflux in the striatum [37], which may explain the observed upregulation of expression for D1R pathway genes after pridopidine treatment. 

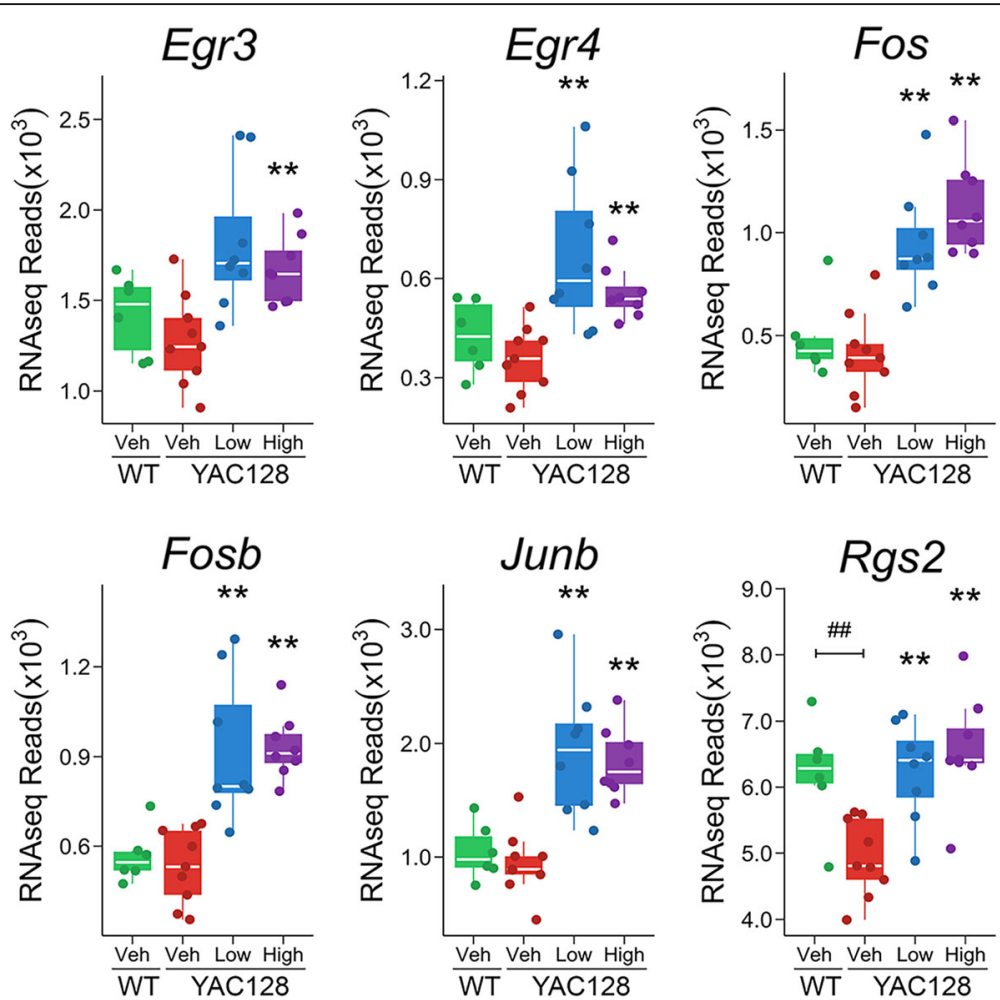

Fig. 6 RNAseq differential expression analysis of CAMP-related genes in the YAC128 striatum. Shown are RNAseq results for differentially expressed genes in the YAC128 striatum after pridopidine treatment. "**" and "\#\#" represent significant (Adj. p-val <0.05) differential expression in YAC128 Veh-WT Veh and YAC128 Low/High-YAC128 Veh contrasts, respectively. "High" = 30 mg/kg of pridopidine; "Low" = 10 mg/kg of pridopidine; "Veh" = vehicle

\section{A Top 10 Wikipathway Analysis Pathways}

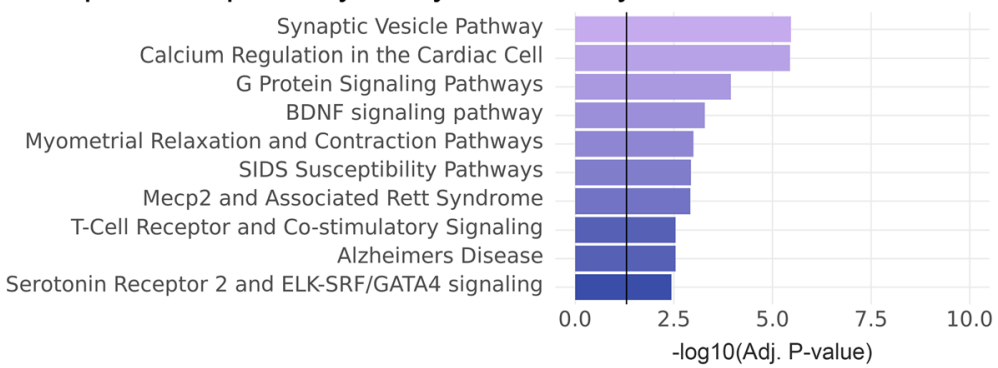

B Top 10 GO Biological Processes

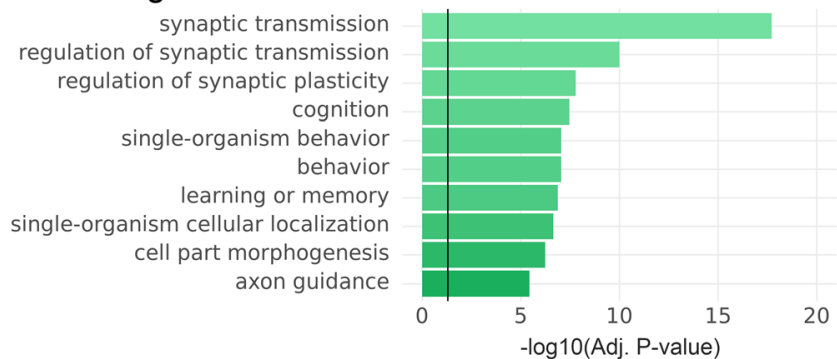

Fig. 7 Pathway and differential exon/splice junction analysis in the YAC128 striatum after pridopidine treatment. Pathway analysis was performed on genes that demonstrated pridopidine induced alternative exon/junction usage at a high dose (30 mg/kg). a Top 10 significant (Adj. $p$-val < 0.05) pathways from the WikiPathway database. $\mathbf{b}$ Top 10 significant (Adj. $p$-val < 0.05) pathways from the Gene Ontology (GO) pathway database 
In the WT striatum, dopamine is a central regulator of cAMP activity in both D1 and D2 receptor-expressing neurons, namely, medium spiny neurons, where D1Rs and D2Rs have opposing effects on cAMP levels [38]. Previous studies of HD postmortem brain tissue and animal models have shown that cAMP signaling becomes deregulated in the striatum of humans and animal HD models [9, 39, 40]. Restoration of cAMP levels reduced $\mathrm{mHtt}$ aggregates in the striatum of $\mathrm{R} 6 / 2 \mathrm{HD}$ mice [40], underscoring the importance of rescuing striatal cAMP signaling. In the YAC128 striatum, we observed downregulation of cAMP pathway genes, which are upregulated after treatment with pridopidine (Figs. 5, 6, and 8).

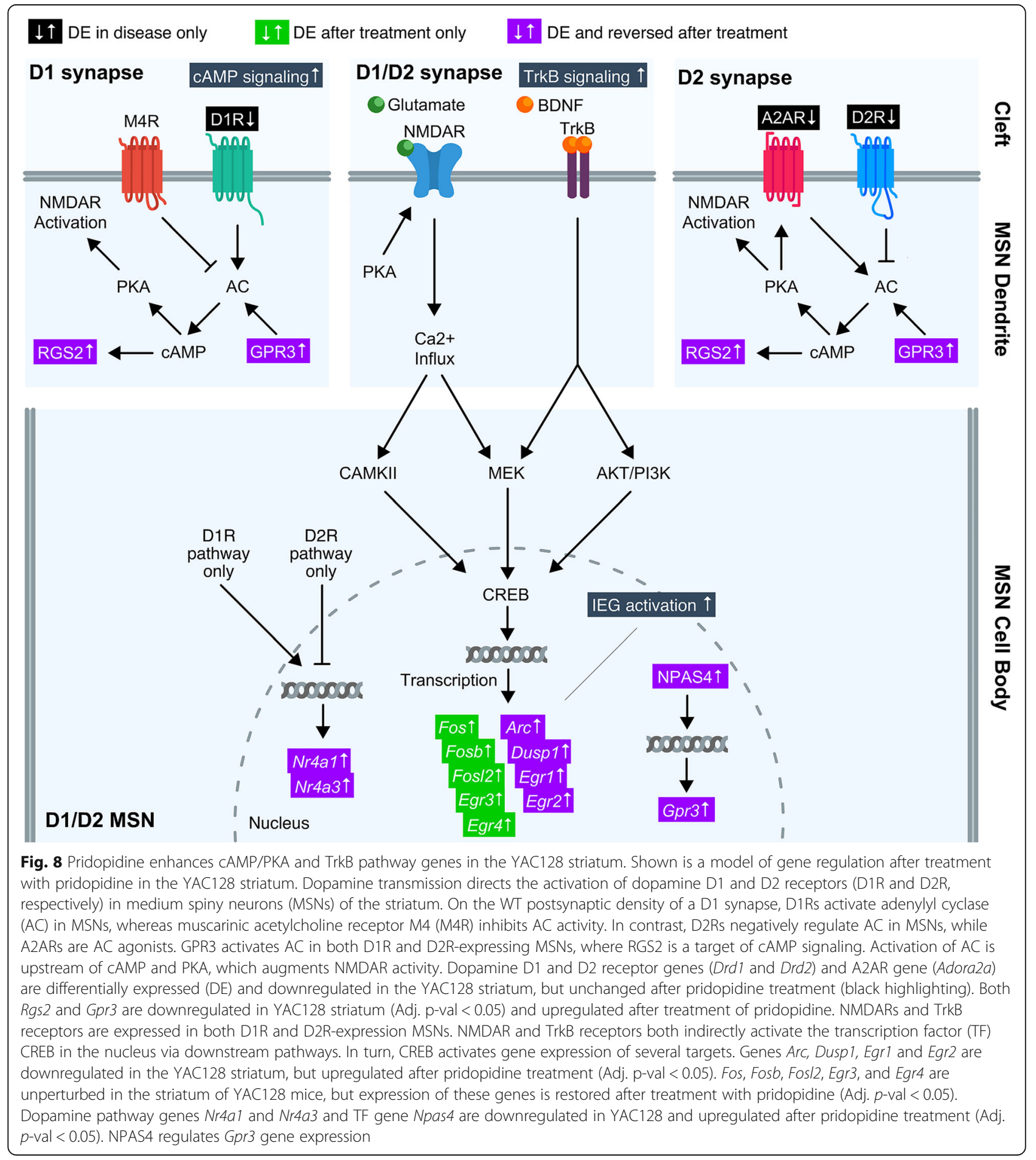


In agreement with Garcia-Miralles et al. [19], we noted reversal of compromised expression of dopamine receptor genes (Drd1 and $D r d 2)$ after pridopidine treatment in the YAC128 striatum. However, reversal of Drd1 and Drd2 expression was only nominally significant after treatment with either the 10 or $30 \mathrm{mg} / \mathrm{kg}$ dose of pridopidine [19]. Therefore, pridopidine could partly restore dopamine-cAMP signaling via compensatory mechanisms. One possibility is that pridopidine induces post-translational regulation of the D1R protein. PSD-95 has been shown to increase D1R surface level expression [41], regulate D1R internalization, and D1R-cAMP signaling $[42,43]$. In the striatum, wild-type HTT binds to postsynaptic density protein 95 and promotes its clustering (PSD-95) [42, 44], whereas mHTT lacks binding affinity to PSD-95 [44]. In agreement with increased D1R activity, compromised expression of D1R-regulated genes $N r 4 a 1$ and $N r 4 a 3$ is rescued after treatment with either 10 or $30 \mathrm{mg} / \mathrm{kg}$ pridopidine in the YAC128 striatum (Adj. $p$-val $<0.05$, Fig. 5).

In addition to dopamine signaling, other signal transduction pathways regulate cAMP response targets, which may also explain the putative effect of pridopidine on cAMP signaling. For example, we identified two additional cAMP-related DEGs (Npas4 and Gpr3) upregulated after treatment with pridopidine in the YAC128 striatum (Additional file 6: Figure S1). Activity-dependent NPAS4 has been shown to upregulate both $B D N F$ and Gpr3 expression in cultured excitatory and inhibitory neurons, respectively [45]. GPR3 is a constitutive activator of cAMP signaling via adenylyl cyclase (AC) [46, 47]. Interestingly, Npas4 gene expression is compromised in the YAC128 striatum, but rescued after pridopidine treatment with either dose (10 or $30 \mathrm{mg} / \mathrm{kg}$, Adj. $p$-val $<0.05$, Fig. 5). In addition, Gpr3 gene expression is downregulated in the YAC128 striatum, whereas striatal expression of Gpr3 is upregulated after either 10 or $30 \mathrm{mg} / \mathrm{kg}$ pridopidine treatment in YAC128 mice (Additional file 5: Figure S5, Adj. p-val <0.05). Taken together, this suggests that pridopidine could partly rescue dysregulated cAMP signaling by modulating Npas4 and Gpr3 gene expression. In addition to the GPR3-cAMP pathway, BDNF-TrkB signaling has also been shown to activate cAMP response element binding (CREB) protein activity and thus facilitate gene expression in cultured striatal neurons [26]. In other words, pridopidine may induce transcription by binding to S1R, which leads to enhanced BDNF activity, in turn activating gene and splice-variant expression. This alternative mechanism is also supported by the fact that pridopidine induces BDNF release in neuroblastoma cells [30].

Recently, it was demonstrated that treatment with $30 \mathrm{mg} / \mathrm{kg}$ of pridopidine rescues motor deficiencies in
YAC128 mice, whereas no effect was detected in YAC128 animals treated with $10 \mathrm{mg} / \mathrm{kg}$ of pridopidine [19]. In agreement with this observation, we report a broader effect of $30 \mathrm{mg} / \mathrm{kg}$ pridopidine on gene expression in the YAC128 striatum compared to the $10 \mathrm{mg} / \mathrm{kg}$ dose, but also report that either dose reverses disease associated gene expression. The effect of $30 \mathrm{mg} / \mathrm{kg}$ pridopidine on motor function diminishes during the progression of the disease [19], and the lowest locomotor performance is observed between 10 and 12 months of age when mice are very ill. Given that RNA samples for this study were collected during the decline of motor activity in $30 \mathrm{mg} / \mathrm{kg}$ pridopidine-treated YAC128 mice, it is difficult to correlate improvement in motor deficit and pridopidine-induced gene expression in the striatum of YAC128 animals. Moreover, our study showed that pridopidine induces a robust gene expression signal when treatment begins early in disease course. This may suggest that in humans, pridopidine may be more effective if started in early disease stages. For both of these reasons, a longitudinal study with earlier time points would better illuminate the link between gene expression and motor behavior after treatment with pridopidine in YAC128 mice.

\section{Conclusions}

In conclusion, pridopidine reverses HD associated changes in transcription at the pathway, gene and splice-variant level. Pathways with transcriptomic aberrations in the YAC128 mouse that are restored to WT levels by pridopidine treatment include BDNF, D1R, GR, cAMP, and calcium signaling. These pathways together are known to interact, and likely positively feed into each other downstream of pridopidine treatment, to relieve HD associated motor symptoms. Beneficial effects when treatment is initiated early, before symptoms are manifest, tracks with trends observed in clinical trials. Studying the effect of pridopidine at multiple time points over the course of treatment against transcriptomic aberrations in YAC128 will reveal additional regulatory dynamics. The results in this study, all taken together, support exploring pridopidine's role as a therapeutic for neuroprotection in HD and similar neurological movement disorders.

\section{Additional files}

Additional file 1: Table S1. Adjusted p-val range and fold change range for differential expression and DUEJ genes meeting adj $\mathrm{p}$-val $<0.05$ cutoff. (XLSX $11 \mathrm{~kb}$ )

Additional file 2: Table S2. Gene Ontology pathway analysis of genes differentially expressed in the mouse striatum. (XLSX $27 \mathrm{~kb}$ )

Additional file 3: Table S3. Transcription factor enrichment analysis of genes differentially expressed in the mouse striatum. (XLSX $18 \mathrm{~kb}$ ) 
Additional file 4: Table S4. $\mathrm{qPCR}$ validation of striatal gene expression identified in RNAseq and pathway analysis. (XLSX $10 \mathrm{~kb}$ )

Additional file 5: Table S5. Pathway analysis of alternatively spliced genes identified after high dose treatment with pridopidine. (XLSX $31 \mathrm{~kb}$ )

Additional file 6: Figure S1. Pridopidine reverses downregulation of $G$ Protein-Coupled Receptor 3 (Gpr3) gene expression in the striatum of YAC128 mice. Shown are RNAseq results for Gpr3 in the YAC128 striatum after pridopidine treatment. "**" and "\#\#" represent significant (Adj. p-val $<0.05)$ differential expression in YAC128 Veh-WT Veh and YAC128 LoW/ High-YAC128 Veh contrasts, respectively. "High" $=30 \mathrm{mg} / \mathrm{kg}$ of pridopidine; "Low" = 10 mg/kg of pridopidine; "Veh" = vehicle. (PDF $151 \mathrm{~kb}$ )

\section{Abbreviations}

AC: Adenylyl cyclase; BDNF: Brain-derived neurotrophic factor; CAMP: Cyclic AMP; ChEA: ChIP Enrichment Analysis; CREB: cAMP response element binding; D1R: Dopamine D1 receptor; DE: Differential expression; DUEJ: Differential usage of exon and splice junction; ER: Endoplasmic reticulum; GO: Gene ontology; GPe: External segment of the globus pallidus; Gpr3: G protein-coupled receptor 3; GR: Glucocorticoid receptor; GSEA: Gene set enrichment analysis; HD: Huntington disease; Htt: Huntingtin; M4R: Muscarinic acetylcholine receptor M4; MAQC: MicroArray quality control; mHtt: Mutant Htt; MSNs: Medium spiny neurons; NMDA: N-methyl-Daspartate; QoRTs: Quality of RNA-Seq toolset; SNr: Pars reticulata of the substantia nigra; STN: Subthalamic nucleus; TF: Transcriptional factors; TMS: Total Motor Score; TrkB: Tropomyosin receptor kinase B; WT: Wild-type; б1r: Sigma-1 receptor

\section{Funding}

Teva Pharmaceuticals provided funding for the study.

\section{Availability of data and materials}

The datasets used and/or analysed during the current study are available from the corresponding author on reasonable request.

\section{Authors' contributions}

All authors discussed the results and contributed to the manuscript. RK, JD, MG, MP, DL, MGM, LJT, MEB, and MRH designed the study and participated in its design and coordination. RK, JR, YC, and REC processed and analyzed gene expression data. RK, JD, JR, MG, DL, IG, MEB, MP, BZ, and MRH drafted and revised the manuscript. All authors read and approved the final manuscript.

\section{Authors' information}

Information for all the co-authors is listed in the title page.

\section{Ethics approva}

All mouse experiments were performed with the approval of and in accordance with the Institutional Animal Care and Use Committee at the Biomedical Sciences Institute at the Agency for Science, Technology and Research.

\section{Competing interests}

RK, JR, YC, REC, BZ are employees of Immuneering Corporation. JD, MEB, DL, $M G, I G$, and MRH are employees of Teva Pharmaceutical. Teva Pharmaceuticals played no role in the treatment or testing of animals, or the collection, or analysis of the results.

\section{Publisher's Note}

Springer Nature remains neutral with regard to jurisdictional claims in published maps and institutional affiliations.

\section{Author details}

${ }^{1}$ Immuneering Corporation, Cambridge, MA 02142, USA. ${ }^{2}$ Research and

Development, Teva Pharmaceutical Industries Ltd, Netanya, Israel.

${ }^{3}$ Translational Laboratory in Genetic Medicine, Agency for Science,

Technology and Research, Singapore (A*STAR), Singapore 138648, Singapore.

${ }^{4}$ Centre for Molecular Medicine and Therapeutics, Child and Family Research

Institute, University of British Columbia, Vancouver, BC V5Z 4H4, Canada.
${ }^{5}$ Department of Medicine, Yong Loo Lin School of Medicine, National University of Singapore, Singapore 117597, Singapore.

Received: 9 April 2018 Accepted: 13 May 2018

Published online: 21 May 2018

\section{References}

1. Macdonald M. A novel gene containing a trinucleotide repeat that is expanded and unstable on Huntington's disease chromosomes. Cell. 1993; 72:971-83.

2. Foroud T, Gray J, Ivashina J, Conneally PM. Differences in duration of Huntington's disease based on age at onset. J Neurol Neurosurg Psychiatry. 1999;66:52-6.

3. Colin E, Zala D, Liot G, Rangone H, Borrell-Pagès M, Li X-J, et al. Huntingtin phosphorylation acts as a molecular switch for anterograde/retrograde transport in neurons. EMBO J. 2008;27:2124-34.

4. Miller BR, Bezprozvanny I. Corticostriatal circuit dysfunction in Huntington's disease: intersection of glutamate, dopamine and calcium. Future Neurol. 2010;5:735-56.

5. Gauthier LR, Charrin BC, Borrell-Pagès M, Dompierre JP, Rangone $H_{\text {, }}$ Cordelières FP, et al. Huntingtin controls neurotrophic support and survival of neurons by enhancing BDNF vesicular transport along microtubules. Cell. 2004;118:127-38.

6. André VM, Fisher YE, Levine MS. Altered balance of activity in the striatal direct and indirect pathways in mouse models of Huntington's disease. Front Syst Neurosci. 2011:5:46.

7. Plotkin JL, Day M, Peterson JD, Xie Z, Kress GJ, Rafalovich I, et al. Impaired TrkB receptor signaling underlies corticostriatal dysfunction in Huntington's disease. Neuron. 2014;83:178-88.

8. Nguyen $\mathrm{KQ}$, Rymar W, Sadikot AF. Impaired TrkB signaling underlies reduced BDNF-mediated trophic support of striatal neurons in the R6/2 mouse model of Huntington's disease. Front Cell Neurosci. 2016;10:37.

9. Bibb JA, Yan Z, Svenningsson P, Snyder GL, Pieribone VA, Horiuchi A, et al. Severe deficiencies in dopamine signaling in presymptomatic Huntington's disease mice. Proc Natl Acad Sci U S A. 2000:97:6809-14.

10. de Yebenes JG, Landwehrmeyer B, Squitieri F, Reilmann R, Rosser A, Barker RA, et al. Pridopidine for the treatment of motor function in patients with Huntington's disease (MermaiHD): a phase 3, randomised, double-blind, placebo-controlled trial. Lancet Neurol. 2011;10:1049-57.

11. The Huntington Study Group HART Investigators. A randomized, doubleblind, placebo-controlled trial of pridopidine in Huntington's disease. Mov Disord. 2013:28:1407-15.

12. Sahlholm K, Sijbesma JWA, Maas B, Kwizera C, Marcellino D, Ramakrishnan NK, et al. Pridopidine selectively occupies sigma-1 rather than dopamine D2 receptors at behaviorally active doses. Psychopharmacology. 2015;232:3443-53.

13. Ponten $\mathrm{H}$, Kullingsjö J, Sonesson C, Waters S, Waters N, Tedroff J. The dopaminergic stabilizer pridopidine decreases expression of L-DOPAinduced locomotor sensitisation in the rat unilateral 6-OHDA model. Eur J Pharmacol. 2013:698:278-85.

14. Dyhring T, Nielsen E $\varnothing$, Sonesson C, Pettersson F, Karlsson J, Svensson P, et al. The dopaminergic stabilizers pridopidine (ACR16) and (-)-OSU6162 display dopamine D2 receptor antagonism and fast receptor dissociation properties. Eur J Pharmacol. 2010;628:19-26.

15. Ryskamp D, Wu J, Geva M, Kusko R, Grossman I, Hayden M, et al. The sigma1 receptor mediates the beneficial effects of pridopidine in a mouse model of Huntington disease. Neurobiol Dis. 2017;97:46-59.

16. Squitieri F, Di Pardo A, Favellato M, Amico E, Maglione V, Frati L Pridopidine, a dopamine stabilizer, improves motor performance and shows neuroprotective effects in Huntington disease R6/2 mouse model. J Cell Mol Med. 2015;19(11):2540-548.

17. Altar CA, Cai N, Bliven T, Juhasz M, Conner JM, Acheson AL, et al. Anterograde transport of brain-derived neurotrophic factor and its role in the brain. Nature. 1997:389:856-60

18. Slow EJ, van Raamsdonk J, Rogers D, Coleman SH, Graham RK, Deng Y, et al. Selective striatal neuronal loss in a YAC128 mouse model of Huntington disease. Hum Mol Genet. 2003:12:1555-67.

19. Garcia-Miralles M, Geva M, Tan JY, et al. Early pridopidine treatment improves behavioral and transcriptional deficits in YAC128 Huntington disease mice. JCI Insight. 2017;2(23):e95665. https://doi.org/10.1172/jci.insight.95665.

20. Dobin A, Davis CA, Schlesinger F, Drenkow J, Zaleski C, Jha S, et al. STAR: ultrafast universal RNA-seq aligner. Bioinformatics. 2013;29:15-21. 
21. Robinson MD, McCarthy DJ, Smyth GK. edgeR: a Bioconductor package for differential expression analysis of digital gene expression data. Bioinformatics. 2010;26:139-40.

22. Su Z, Łabaj PP, Li S, Thierry-Mieg J, Thierry-Mieg D, et al. Seqc/Maqc-lii Consortium. A comprehensive assessment of RNA-seq accuracy, reproducibility and information content by the sequencing quality control consortium. Nat Biotechnol 2014;32:903-914.

23. Ritchie ME, Phipson B, Wu D, Hu Y, Law CW, Shi W, et al. Limma powers differential expression analyses for RNA-sequencing and microarray studies. Nucleic Acids Res. 2015;43:e47.

24. Subramanian A, Tamayo P, Mootha VK, Mukherjee S, Ebert BL, Gillette MA, et al. Gene set enrichment analysis: a knowledge-based approach for interpreting genome-wide expression profiles. Proc Natl Acad Sci. 2005;102: 15545-50.

25. Sato H, Horikawa Y, lizuka K, Sakurai N, Tanaka T, Shihara N, et al. Large-scale analysis of glucocorticoid target genes in rat hypothalamus. J Neurochem. 2008:106:805-14.

26. Gokce O, Runne H, Kuhn A, Luthi-Carter R. Short-term striatal gene expression responses to brain-derived neurotrophic factor are dependent on MEK and ERK activation. PLoS One. 2009;4:e5292.

27. Cadet $J$, Jayanthi S, McCoy MT, Beauvais G, Cai NS. Dopamine D1 receptors, regulation of gene expression in the brain, and neurodegeneration. CNS Neurol Disord Drug Targets. 2010;9:526-38.

28. Maqc Consortium SL, Shi L, Reid LH, Jones WD, Shippy R, et al. The MicroArray quality control (MAQC) project shows inter- and intraplatform reproducibility of gene expression measurements. Nat Biotechnol. 2006;24:1151-61.

29. Chen EY, Tan CM, Kou Y, Duan Q, Wang Z, Meirelles GV, et al. Enrichr: interactive and collaborative HTML5 gene list enrichment analysis tool. BMC Bioinformatics. 2013;14:1-14.

30. Geva M, Kusko R, Soares H, Fowler KD, Birnberg T, Barash S, et al. Pridopidine activates neuroprotective pathways impaired in Huntington disease. Hum Mol Genet. 2016;25(18):3975-987.

31. Aziz NA, Pijl H, Frölich M, van der Graaf AWM, Roelfsema F, Roos RAC. Increased hypothalamic-pituitary-adrenal axis activity in Huntington's disease. J Clin Endocrinol Metab. 2009;94:1223-8.

32. Dong X, Tsuji J, Labadorf A, Roussos P, Chen J-F, Myers RH, et al. The role of H3K4me3 in transcriptional regulation is altered in Huntington's disease. PLoS One. 2015;10:e0144398.

33. Choi Y-S, Lee B, Cho H-Y, Reyes IB, Pu X-A, Saido TC, et al. CREB is a key regulator of striatal vulnerability in chemical and genetic models of Huntington's disease. Neurobiol Dis. 2009;36:259-68.

34. Taymans J-M, Leysen JE, Langlois X. Striatal gene expression of RGS2 and RGS4 is specifically mediated by dopamine D1 and D2 receptors: clues for RGS2 and RGS4 functions. J Neurochem. 2003;84:1118-27.

35. Xie Y, Hayden MR, Xu B. BDNF overexpression in the forebrain rescues Huntington's disease phenotypes in YAC128 mice. J Neurosci. 2010;30:14708-18.

36. Maheshwari M, Bhutani S, Das A, Mukherjee R, Sharma A, Kino Y, et al. Dexamethasone induces heat shock response and slows down disease progression in mouse and fly models of Huntington's disease. Hum Mol Genet. 2014;23:2737-51.

37. Ponten H, Kullingsjö J, Lagerkvist S, Martin P, Pettersson F, Sonesson C, et al. In vivo pharmacology of the dopaminergic stabilizer pridopidine. Eur J Pharmacol. 2010;644:88-95.

38. Nagai T, Yoshimoto J, Kannon T, Kuroda K, Kaibuchi K. Phosphorylation signals in striatal medium spiny neurons. Trends Pharmacol Sci. 2016;37:858-71.

39. Gines S, Seong IS, Fossale E, Ivanova E, Trettel F, Gusella JF, et al. Specific progressive CAMP reduction implicates energy deficit in presymptomatic Huntington's disease knock-in mice. Hum Mol Genet. 2003;12:497-508.

40. Lin J-T, Chang W-C, Chen H-M, Lai H-L, Chen C-Y, Tao M-H, et al. Regulation of feedback between protein kinase a and the proteasome system worsens Huntington's disease. Mol Cell Biol. 2013;33:1073-84.

41. Porras G, Berthet A, Dehay B, Li Q, Ladepeche L, Normand E, et al. PSD-95 expression controls I-DOPA dyskinesia through dopamine D1 receptor trafficking. J Clin Invest. 2012;122:3977-89.

42. Parsons MP, Kang R, Buren C, Dau A, Southwell AL, Doty CN, et al. Bidirectional control of postsynaptic density-95 (PSD-95) clustering by huntingtin. J Biol Chem. 2014;289:3518-28.

43. Zhang J, Vinuela A, Neely MH, Hallett PJ, Grant SGN, Miller GM, et al. Inhibition of the dopamine D1 receptor signaling by PSD-95. J Biol Chem. 2007;282:15778-89.
44. Sun Y, Savanenin A, Reddy PH, Liu YF. Polyglutamine-expanded huntingtin promotes sensitization of $\mathrm{N}$-methyl-D-aspartate receptors via post-synaptic density 95. J Biol Chem. 2001;276:24713-8.

45. Spiegel I, Mardinly A, Gabel H, Bazinet J, Couch C, Tzeng C, et al. Npas4 regulates excitatory-inhibitory balance within neural circuits through cell type-specific gene programs. Cell. 2014;157:1216-29.

46. Eggerickx D, Denef JF, Labbe O, Hayashi Y, Refetoff S, Vassart G, et al. Molecular cloning of an orphan G-protein-coupled receptor that constitutively activates adenylate cyclase. Biochem J. 1995;309(Pt 3):837-43.

47. Valverde $O$, Célérier E, Baranyi M, Vanderhaeghen P, Maldonado R, Sperlagh $B$, et al. GPR3 receptor, a novel actor in the emotional-like responses. PLoS One. 2009;4:e4704

\section{Ready to submit your research? Choose BMC and benefit from:}

- fast, convenient online submission

- thorough peer review by experienced researchers in your field

- rapid publication on acceptance

- support for research data, including large and complex data types

- gold Open Access which fosters wider collaboration and increased citations

- maximum visibility for your research: over $100 \mathrm{M}$ website views per year

At BMC, research is always in progress.

Learn more biomedcentral.com/submissions 